\title{
Decentralised Energy Management System to Virtual Power Plants
}

\author{
J.A. Barbosa, R.P.S. Leão, C.F.P. Lima, M.C. O. Rego and F.L.M. Antunes \\ Department of Electrical Engineering \\ Federal University of Ceara \\ Campus do Pici - Caixa Postal 6001, CEP: 60455-760 Fortaleza (Brazil) \\ Phone/Fax number:+0055 85 3366.9580, e-mail: jalmada@oi.com.br, rleao@dee.ufc.br, \\ carlosfelipepl@hotmail.com,marcos337@hotmail.com, fantunes@dee.ufc.br
}

\begin{abstract}
.
This paper focuses on the steady-state analysis of location and control of distributed power generators encompassing a virtual power plant (VPP). The significant increase worldwide in distributed generation from renewable energy has been largely due to the concern with the environment, the grid access and the strong support policies for the promotion of renewable electricity. Deployment of distributed power plants has contributed to the new concept of VPP as a solution to handle the mix of conventional and distributed energy sources. Produced energy from even small scale generators will be utilized in energy markets and can contribute to the enhancement of the electrical power system. When aggregated, the group of DG would gain access and visibility across the energy markets and the system operation will benefit from optimal use of all available capacity and increased efficiency of operation.
\end{abstract}

\section{Key words}

Distributed generation, virtual power plant, decentralized energy management, information and communication technology.

\section{Introduction}

The meaningful growth of distributed power generation from renewable energy sources in the last decade has been primarily driven by environmental concerns, the grid access and the strong support policies for the promotion of renewable electricity. A great share of distributed generation (DG) units feed a respectable amount of electrical energy directly into the distribution level. The dispersed and stochastic characteristic of the renewable based DG units needs to be properly managed in order to guarantee security and quality of supply as well as to improve the system efficiency at an economic level. To take full advantage of the DG concept, decentralised control paradigm has been considered that ensures a coordinated operation of the dispersed units. When aggregated, the group of DG would gain access and visibility across the energy markets and the system operation will benefit from optimal use of all available capacity and increased efficiency of operation [1]-[3]. A cluster of distributed generation installations, controllable loads and storage systems when aggregated and collectively run by a central control unit by means of modern information and communication technologies is called virtual power plant (VPP) [4]. VPP can facilitate the decentralisation of the system management necessary for systems with a large number of small-scale. The VPP should act like a conventional power plant which keeps the power system balanced and guarantees the appropriate power quality level.

This paper deals with the location and control of three DG units in an $11 \mathrm{kV}$ commercial distribution system. The power losses, voltage drop and voltage regulation are taken into consideration to allocate the units through a global performance index [5]. Three different strategies of power dispatch are applied to the cluster of DG, which are termed the basic, the intelligent and the efficient control strategies [6]. The system performance is evaluated considering the DG units either operating with constant power factor or constant bus voltage.

The paper is outlined with four sections as follows: section 1 depicts the new moving experienced by the distribution system with the proliferation of distributed generation and the paper goals; section 2 presents the Brazilian regulation on distributed generation; the characteristics and parameters of the distribution testsystem as well as the location of the DG units are presented in section 3; the DG dispatch strategies are described in section 4 and finally the conclusion is presented in section 5 .

\section{The Brazilian Regulation to Distributed Generation}

The distribution power system in Brazil is regulated by a set of rules compiled in a document known as the Distribution Procedures (Prodist) [7]. The Prodist disciplines the relationship between the power distribution utilities, consumers and suppliers connected to the distribution grid under $230 \mathrm{kV}$. At present the 
Prodist rules are under revision by the National Electrical Energy Regulatory Agency (Aneel), in special the two modules which deal with Access to the Distribution System and the Power Quality besides further improvement needed in the other modules [8],[9]. The two mentioned modules are highly related to the distributed generation issues. The most significant rules related to the distributed generation in Prodist will be summarized next.

\section{A. The Connection Procedures}

The connection of DG units to the distribution system in Brazil is established by contract between the producer and the local utility company. When the voltage connection is above $69 \mathrm{kV}$ the National Operator System (ONS) is called upon to coordinate the contract. The connection is accomplished in a.c. $60 \mathrm{~Hz}$. The producer is the only one in charge of the appropriate synchronization of its assets with the distribution system accessed.

The connection procedures should pay attention to the pattern given by performance indices and quality of service of the distribution. The producer is enabled to indicate the connection point of interest. The definition of the connection points for the generation plants is based on the least global cost criteria. Studies results with alternative connection points are required to be presented by the producer to the utility.

The generation plants connected to the high voltage distribution system (rms voltage equal to or above $69 \mathrm{kV}$ and under $230 \mathrm{kV}$ ) can participate of the Automatic Generation Control and the Generation Shutdown Schedule.

The generation dispatch of the plants connected to the distribution system can be either centralized, in this case performed by the ONS, or non-centralized when performed by the initiative of each producer. The distribution utility company can aggregate the generation plants connected to the distribution grid in a given area to form a Distributed Generation Dispatch Centre (DGDC). The DGDC can supervise and command the respective generation plants; it also can coordinate and control the plants not dispatched by the ONS. The DGDC functions are among others: to limit the injection of power into the distribution system; control the voltage and the reactive power; to define the production of energy.

The aggregated generation plants form what is considered to be a Virtual Power Plant (VPP).

\section{B. Voltage and Protection Requirements to DG Connection}

The generation plants can be connected to the low voltage distribution system (rms phase-to-phase voltage equal to or inferior to $1 \mathrm{kV}$ ). However, there is any incentive to the low voltage connected consumer to make it an electricity producer.
Table 1 shows the voltage levels considered for connection of generation plants according to the installed power [8].

Table I. - Voltage Levels to Connect GD Units.

\begin{tabular}{|l|l|}
\hline \multicolumn{1}{|c|}{ INSTALLED POWER } & \multicolumn{1}{c|}{ CONNECTION VOLTAGE } \\
\hline$<10 \mathrm{~kW}$ & Low voltage (one-phase) \\
\hline $10 \mathrm{a} 75 \mathrm{~kW}$ & Low voltage (three-phase) \\
\hline 76 a $500 \mathrm{~kW}$ & $\begin{array}{l}\text { Low voltage (three-phase) } / \\
\text { Medium voltage }\end{array}$ \\
\hline $501 \mathrm{~kW}$ a $30 \mathrm{MW}$ & Medium voltage / High voltage \\
\hline$>30 \mathrm{MW}$ & High voltage \\
\hline
\end{tabular}

Table II shows the minimal protection requirements at the point of common coupling of the generation plant [8].

Table II. - Minimal Protection Devices.

\begin{tabular}{|l|l|l|l|}
\hline \multirow{2}{*}{ ProteCtION DEVICE } & \multicolumn{3}{|c|}{ InSTALLED POWER } \\
\cline { 2 - 4 } & $<10 \mathrm{~kW}$ & $\begin{array}{l}10 \mathrm{~kW} \text { a } \\
500 \mathrm{~kW}\end{array}$ & $>500 \mathrm{~kW}$ \\
\hline Switching device & yes & yes & yes \\
\hline Interruption device & yes & yes & yes \\
\hline Coupling transformer & no & yes & yes \\
\hline $\begin{array}{l}\text { Under- and over- voltage } \\
\text { protection }\end{array}$ & yes & yes & yes \\
\hline $\begin{array}{l}\text { Under- and over- } \\
\text { frequency protection }\end{array}$ & yes & yes & yes \\
\hline $\begin{array}{l}\text { Unbalanced current } \\
\text { protection }\end{array}$ & no & no & yes \\
\hline $\begin{array}{l}\text { Unbalanced voltage } \\
\text { protection }\end{array}$ & no & no & yes \\
\hline Directional over-current & no & no & yes \\
\hline $\begin{array}{l}\text { Over-current with } \\
\text { voltage restriction }\end{array}$ & no & no & yes \\
\hline
\end{tabular}

The protection system of the generation plant has to be in compliance with that of the utility company.

The generation plants with installed power greater than $300 \mathrm{~kW}$ should evaluate the technical conditions to operate isolated taking into account the power quality criteria defined in the Prodist document [8].

\section{Power Quality Procedures}

The steady-state voltage variation limits in the common connection point must be in accordance with the Prodist - Module 8 [9].

The acceptable operation voltage range of the DG units is the same as that given to the distribution utilities and penalties are provided according to the time elapsed out of the prescribed range. Table III classifies the voltage condition according to the voltage range. These voltage ranges are considered during the allocation of the DG units which are presented in the next section. 
Table III. - Operation Voltage Classification

\begin{tabular}{|l|l|}
\hline \multicolumn{1}{|c|}{$\begin{array}{c}\text { VOLTAGE } \\
\text { CONDITION }\end{array}$} & $\begin{array}{c}\text { VARIATION OF THE READING VOLTAGE } \\
\text { (TL) IN RELATION TO THE CONTRACTED } \\
\text { REFERENCE VOLTAGE }(\mathrm{TC})\end{array}$ \\
\hline Adequate & $0,93 \mathrm{TC} \leq \mathrm{TL} \leq 1,05 \mathrm{TC}$ \\
\hline Precarious & $0,90 \mathrm{TC} \leq \mathrm{TL}<0,93 \mathrm{TC}$ \\
\hline Critical & $\mathrm{TL}<0,90 \mathrm{TC}$ ou TL $>1,05 \mathrm{TC}$ \\
\hline
\end{tabular}

The displacement power factor shall range between 0.9 when the generator unit operates overexcited and 0.95 when underexcited [10].

\section{The Distribution System Test}

The evaluation of the location and dispatch strategies were tested on an $11 \mathrm{kV}$ commercial distribution system feeder with 11 nodes, 10 sections, 5 laterals, 9 fixed loads and 3 dynamic loads as shown in Figure 1, with the system data given in Table IV [11].

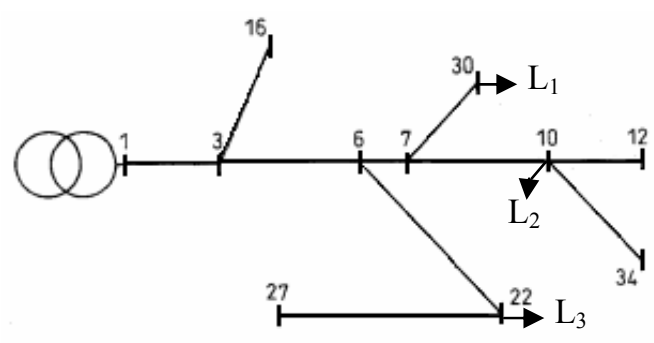

Fig. 1. The one-line distribution system test.

Table IV. - The feeder and laterals parameters.

\begin{tabular}{|l|l|l|l|l|l|}
\hline FROM & TO & $\begin{array}{c}\text { LENGTH } \\
{[\mathrm{KM}]}\end{array}$ & $\begin{array}{c}\mathrm{R} \\
{[\Omega / \mathrm{KM}]}\end{array}$ & $\begin{array}{c}\mathrm{X} \\
{[\Omega / \mathrm{KM}]}\end{array}$ & $\begin{array}{c}\text { LOAD } \\
{[\mathrm{MW}]}\end{array}$ \\
\hline 1 & 3 & 1.15 & 0.195 & 0.080 & 0.414 \\
\hline 3 & 6 & 1.55 & 0.299 & 0.083 & 0.828 \\
\hline 3 & 16 & 1.00 & 0.524 & 0.090 & 0.414 \\
\hline 6 & 22 & 3.20 & 0.299 & 0.083 & 0.760 \\
\hline 6 & 7 & 0.60 & 0.524 & 0.090 & 0 \\
\hline 7 & 10 & 1.40 & 0.524 & 0.090 & 0.832 \\
\hline 7 & 30 & 0.90 & 0.524 & 0.090 & 0.405 \\
\hline 10 & 12 & 0.45 & 0.524 & 0.090 & 0.661 \\
\hline 10 & 34 & 1.20 & 0.524 & 0.090 & 0.410 \\
\hline 22 & 27 & 1.95 & 0.299 & 0.083 & 0.968 \\
\hline Total & & 13.40 & & & 5.691 \\
\hline
\end{tabular}

The feeder constant loads are concentrated at the end terminals of each section as given in Table IV. The load profile of the three variable loads is shown in Figure 2. These loads are connected to the buses 10, 22 and 30 [12]. The peak and the lower demand of the variable loads add up 6.63MW and 3.02MW, respectively.

Three DG units are considered to be connected to the distribution network, which are represented by synchronous generators with nominal power of 2.245MVA, $60 \mathrm{~Hz}, 480 \mathrm{~V}$ phase-to-phase terminal voltage and 0.9 lag power factor. Step-up transformers $0.48 / 11 \mathrm{kV}, 60 \mathrm{~Hz}$, connect the DG units to the distribution system nodes.

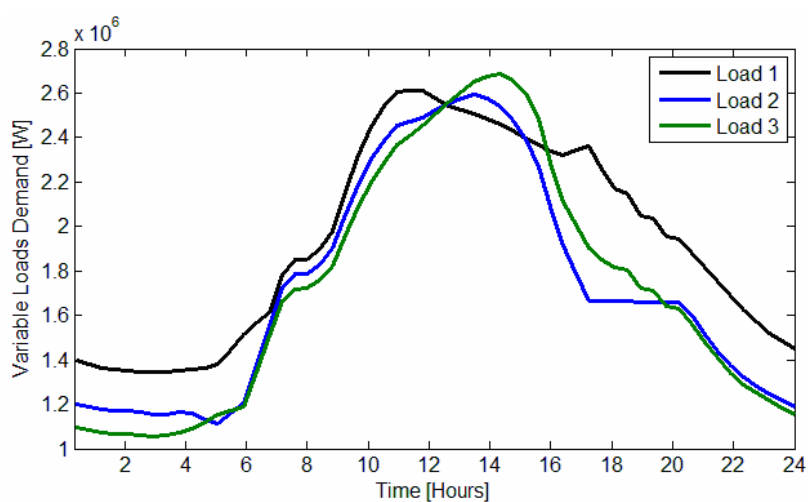

Fig. 2. Power demand curves of the variable loads.

The Power Factory DigSilent software was applied to run the system power flow in order to define the nodes to connect the DG units and the Simulink/Matlab tool was applied to evaluate the units control dispatch to the optimal system configuration.

\section{A. Location of the DG Units}

Connection of DG in distribution networks may create technical and safety problems [13]. To optimize the interaction between conventional power plants and DG so as to guarantee safety and security of supply it is necessary to investigate whether the DG placement can bring about enhancement to the distribution operation. A multi-objective performance index as given in (1) is computed in order to assess the DG impact in view of the nodes voltage levels, the nodes voltage regulation and the active and reactive losses [5].

$$
\begin{gathered}
P I_{k}=\omega_{1}\left(I V D_{k}\right)+\omega_{2}\left(I V R_{k}\right)+ \\
\omega_{3}\left(I P_{k}\right)+\omega_{4}\left(I Q_{k}\right)
\end{gathered}
$$

where

$$
\sum_{i=1}^{4} \omega_{i}=1
$$

$\omega_{i}$ is the weighting factor for each term of the global $P I_{\mathrm{k}}$, $k$ is the likely network configuration, and $I V D_{k}, I V R_{k}, I P_{k}$, and $I Q_{k}$, are the indices related to the voltage drop, voltage regulation, active power losses and reactive power losses, respectively. Each term of $P I_{\mathrm{k}}$ is presented next. A beneficial DG location would result indices near unity values, which means decrease voltage drop, improve voltage regulation and decrease total network losses. Maximum network demand is used in all indices calculation.

Three different network configurations as indicated in Table V have been tested and for each defined scenario the performance index as given in (1) computed.

Table V. - The DG units likely location.

\begin{tabular}{|c|c|c|c|}
\hline SCENARIO K & DG 1 & DG 2 & DG 3 \\
\hline 1 & Bus 30 & Bus 10 & Bus 22 \\
2 & Bus 07 & Bus 12 & Bus 27 \\
3 & Bus 22 & Bus 30 & Bus 27 \\
\hline
\end{tabular}


For each scenario it has been also evaluated the influence of two possible control approaches for the DG synchronous generators, the terminal voltage and the power factor control.

\section{1) Generators with Voltage Control}

When the generators voltages were controlled, the voltages were initially set to $1 \mathrm{pu}$ and then decreased up to a magnitude that could guarantee both the machines nominal power supply and the voltage magnitude of all the distribution nodes within the adequate range according to Aneel recommendation presented in Table III. Figure 3 shows the resulting voltage magnitudes of the distribution nodes for each one of the three scenarios. Table VI gives the adjusted voltage considered for the generators to calculate the performance indices.

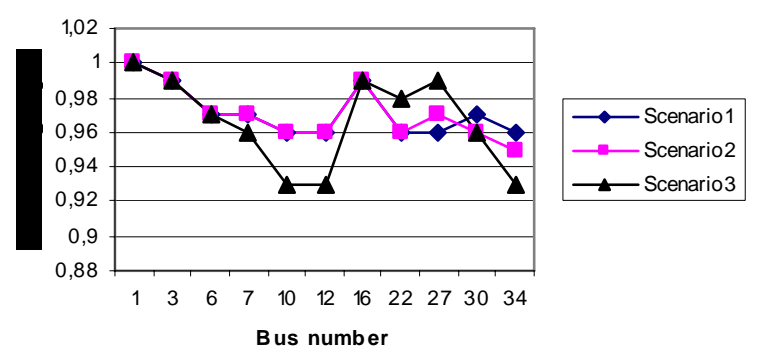

Fig.3. Network bus voltages when the DG units operate with constant voltage.

Table VI. - Voltage setting of the DG

\begin{tabular}{|c|c|c|c|}
\hline SCENARIO K & DG1 & DG2 & DG3 \\
\hline 1 & 0.96 & 0.94 & 0.95 \\
2 & 0.96 & 0.95 & 0.95 \\
3 & 0.96 & 0.95 & 0.97 \\
\hline
\end{tabular}

\section{2) Generators with Power Factor Control}

Alternatively, the generators power factors were at first adjusted to unit, and two nodes (12 and 34) of the distribution system in the scenario $\mathrm{k}=3$ departed from the adequate voltage range as shown in Fig.4.

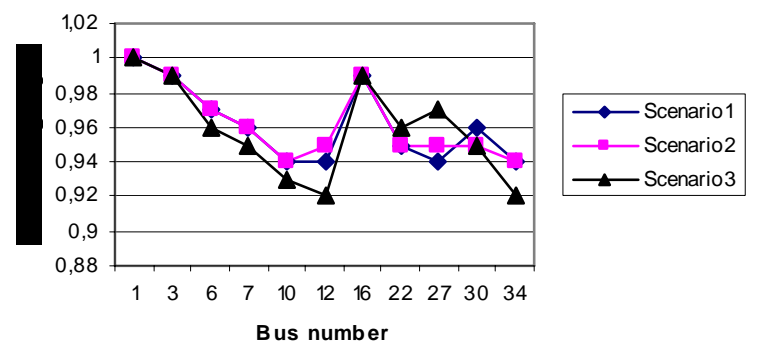

Fig.4. Network bus voltages when the DG units operate with constant power factor.

To bring the network bus voltages to normal, the power factor of the generators were reset to 0.9 lag as shown in Figure 5.

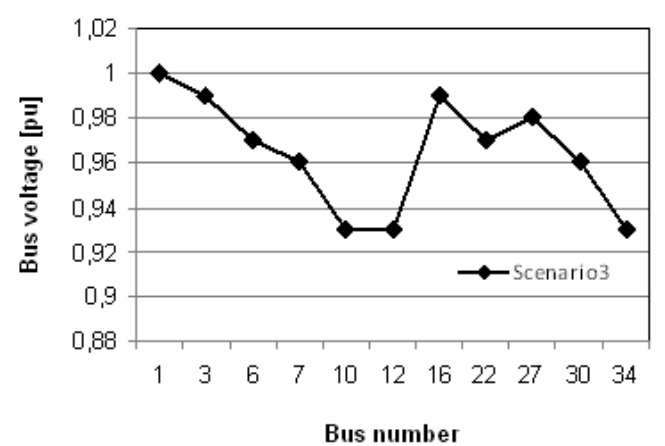

Fig.5. Network bus voltages at scenario 3 when the DG units are controlled by power factor.

\section{3) Voltage Profile Indices}

The indices $I V D_{\mathrm{k}}$ and $I V R_{\mathrm{k}}$ compute respectively the voltage deviation and the voltage regulation as a result of the DG connection.

$$
\begin{gathered}
I V D_{k}=1-\max \left(\frac{\left|\bar{V}_{\phi_{0}}\right|-\left|\bar{V}_{\phi_{i}}^{k}\right|}{\left|\bar{V}_{\phi_{0}}\right|}\right)_{i=1}^{N N-1} \\
I V R_{k}=1-\frac{\sum_{i=1}^{N N-1} \max \left(\left\|\frac{\left|\bar{V}_{\phi_{i}}^{k}\right|-\left|\bar{V}_{\phi_{i}}^{k \min }\right|}{\left|\bar{V}_{\phi_{i}}^{k \min }\right|}\right\|\right)}{N N-1}
\end{gathered}
$$

where $\mathrm{NN}$ is the number of the network nodes, $\bar{V}_{\phi_{0}}$ the phase-to-neutral voltage at the reference node $1, \bar{V}_{\phi_{i}}$ the phase-to-neutral voltage when the system is operating at the maximum demand and $\bar{V}_{\phi_{i}}^{k \text { min }}$ the phase-to-neutral voltage at each node when the system is operating at the minimum load demand with the DG at their maximum power generation.

The computed indices are presented in Table VII for both DG control approaches as explained in 1) and 2). It can be noted that for the $I V D_{\mathrm{k}}$ index, the configuration 1 has presented the best index while scenario 3 has shown the worse indices for both sort of DG control. As far as the $I V R_{\mathrm{k}}$ index is concerned the same value has resulted for the 3 configurations. Better results for both indices, $I V D_{\mathrm{k}}$ and $I V R_{\mathrm{k}}$ were obtained when the DG voltages were controlled.

Table VII. - Voltage drop and voltage regulation indices

\begin{tabular}{c|c|c|c|c}
\hline $\mathrm{k}$ & \multicolumn{2}{|c|}{$I V D_{k}$} & \multicolumn{2}{c}{$I V R_{k}$} \\
\hline & $\begin{array}{c}\text { Voltage } \\
\text { Control }\end{array}$ & $\begin{array}{c}\text { Power Factor } \\
\text { Control }\end{array}$ & $\begin{array}{c}\text { Voltage } \\
\text { Control }\end{array}$ & $\begin{array}{c}\text { Power Factor } \\
\text { Control }\end{array}$ \\
\hline 1 & 0,96 & 0,94 & 0,98 & 0,97 \\
\hline 2 & 0,95 & 0,94 & 0,98 & 0,97 \\
\hline 3 & 0,93 & 0,92 & 0,98 & 0,97 \\
\hline
\end{tabular}




\section{4) Active and Reactive Losses.}

The indices $I P_{k}$ and $I Q_{k}$ counted for the active and reactive losses are given by:

$$
\begin{gathered}
I P_{k}=1-\frac{\operatorname{Re}\left\{\text { Losses }^{k}\right\}}{\operatorname{Re}\left\{\text { Losses }^{0}\right\}} \\
I Q_{k}=1-\frac{\operatorname{Im}\left\{\text { Losses }^{k}\right\}}{\operatorname{Im}\left\{\text { Losses }^{0}\right\}}
\end{gathered}
$$

where Losses $^{\mathrm{k}}$ represents the total system complex losses under the evaluated scenario and Losses $^{0}$ the total complex losses under the system condition without DG.

The results of the computed indices are presented in Table VIII. It can be observed that the DG allocation in the configuration 3 has not improved the power losses as much as the other two configurations. When comparing the two DG control approaches to a given system configuration, it is observed that the power factor control has given better indices, i.e., less active and reactive power losses.

\begin{tabular}{|c|c|c|c|c|}
\hline \multirow[b]{2}{*}{$\mathrm{k}$} & \multicolumn{2}{|r|}{$I P_{k}$} & \multicolumn{2}{|r|}{$I Q_{k}$} \\
\hline & $\begin{array}{l}\text { VOLTAGE } \\
\text { CONTROL }\end{array}$ & $\begin{array}{c}\text { POWER FACTOR } \\
\text { CONTROL }\end{array}$ & $\begin{array}{l}\text { VOLTAGE } \\
\text { CONTROL }\end{array}$ & $\begin{array}{c}\text { POWER FACTOR } \\
\text { CONTROL }\end{array}$ \\
\hline 1 & 0,64 & 0,80 & 0,64 & 0,79 \\
\hline 2 & 0,65 & 0,78 & 0,62 & 0,78 \\
\hline 3 & 0,58 & 0,73 & 0,61 & 0,75 \\
\hline
\end{tabular}

Table VIII. - Index of Active and Reactive Losses.

\section{5) Global Performance Index}

To compute the global performance index as given in (1) a weighting factor equal to 0.3 has been considered to both $I V D_{\mathrm{k}}$ and $I P_{\mathrm{k}}$. Alternatively, it has been assumed to $I V R_{\mathrm{k}}$ and $I Q_{\mathrm{k}}$ a weighting factor equal to 0.2 . Table IX indicates the results for each system configuration. The configuration 1 with the power factor control has reached the best PI. However, when considering the voltage control, the configuration 2 is elected with an index value very close to the highest one.

Table IX. - Global Performance Index

\begin{tabular}{|c|c|c|}
\hline \multirow{2}{*}{$\mathrm{k}$} & \multicolumn{2}{|c|}{$P I_{k}$} \\
\cline { 2 - 3 } & VOLTAGE CONTROL & POWER FACTOR CONTROL \\
\hline 1 & 0,804 & 0,874 \\
2 & 0,871 & 0,866 \\
3 & 0,771 & 0,839 \\
\hline
\end{tabular}

Thus, the selected nodes to connect the DG units are those given by configuration 1 (nodes 10, 22 and 30), which are considered to the application of the control dispatch of the DG presented at next. As far as the DG control strategy, it has been found most appropriate to operate the DG units with a constant power factor for small DG does not have sufficient capacity to regulate the voltage while interconnected. This also avoids having the voltage controls of several small machines competing with each other and the utility voltage regulation scheme.

\section{Dispatch Control of Distributed Generators}

There are two basic control concepts that can be applied to a group of distributed generators, the centralized and decentralized one, with and without communication among the DG units. The main goal of the control concepts presented at following is to reduce the power exchange between the supply utility and the load. Three control strategies based on [6] are applied to the distribution network shown in Figure 1, which presents besides the constant loads three variable loads. The variable loads are programmed to be supplied by the set of DG units optimally allocated as shown previously.

The first control method is simple and it consists of a DG supplying a specific load according to its demand. The second method is a centralized control which aims to define the dispatch for each DG such that the total demand of the variable loads are as much as possible supplied by the DG units. Finally, an efficient control of the cluster of DG is applied which seeks the operation of the DG at their maximum efficiency.

\section{A. Basic Dispatch Control}

The first control method was implemented in only one DG connected in parallel with the grid. The goal is to supply the local load to reduce the energy required from the utility. The method can be extended to other DG units, but they are not integrated with no-communication among them. The utility works as supply backup whenever the demand is superior to the maximum generation capacity of the DG. When the demand is lower than the DG capacity, there is no power exchange between the utility and the load and the DG supplies accordingly the demand required by the variable load.

\section{B. Intelligent Dispatch Control}

When more than one DG can supply the load demand, it is necessary to have communication system to exchange information about the required demand and the available generation. The second simulated method is a centralized control which receives information from the loads and controls the generators to match the demand according to programmed criteria. Figure 6 depicts the so-called intelligent dispatch control. To this approach the communication plays an important role.

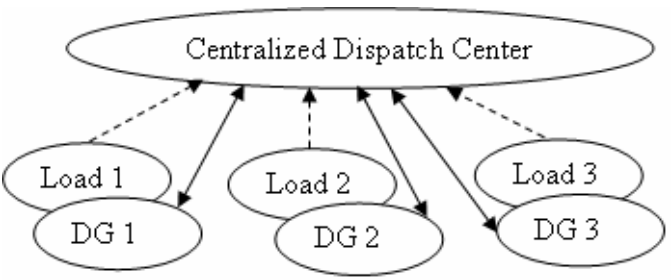

Fig.6. Intelligent dispatch control. 
If a given load is not able to be full supplied by a programmed $\mathrm{DG}$, then based on a predefined priority criteria, as that shown in Table $\mathrm{X}$, the other DG units can supply the remaining load. The power exchange with the utility is only called upon when the total demand can not be matched by the cluster of DG.

Table X. - Generation Priority Schedule for each Load

\begin{tabular}{|c|c|c|c|c|}
\hline $\begin{array}{c}\text { VARIABLE } \\
\text { LOAD }\end{array}$ & $\begin{array}{c}\text { 1ST } \\
\text { PRIORITY }\end{array}$ & $\begin{array}{c}\text { 2ND } \\
\text { PRIORITY }\end{array}$ & $\begin{array}{c}\text { 3RD } \\
\text { PRIORITY }\end{array}$ & $\begin{array}{c}4 \mathrm{TH} \\
\text { PRIORITY }\end{array}$ \\
\hline 1 & GD 1 & GD 2 & GD 3 & Utility \\
2 & GD 2 & GD 3 & GD 1 & Utility \\
3 & GD 3 & GD 1 & GD 2 & Utility \\
\hline
\end{tabular}

For a demand condition required by the three variable loads, around 8:00pm as shown in Figure 2, when Load1 demands 1.95MW, Load2 1.66MW and Load3 1.64MW, Table XI gives the corresponding dispatch for each one of the three DG connected at nodes 30, 10 and 22 .

Table XI. - Simulation result of the Intelligent Dispatch Control

\begin{tabular}{|l|l|}
\hline Demanded Power & \multicolumn{1}{|c|}{ DG Generated Power } \\
\hline Load 1 - 1.95 MW & DG 1-1.79MW \\
Load 2-1.66 MW & DG 2 -1.66MW + 130kW \\
Load 3-1.64 MW & DG 3 - 1.64MW $+30 \mathrm{~kW}$ \\
\hline
\end{tabular}

As it can be observed in Table XI, Load 1 demands power greater than the maximum generation capacity of DG 1. It can be recalled that it has been assumed that the DG is operated with a constant power factor which has been set to unity and in this case, according to the capability curve of the DG, its maximum allowed active power is equal to $1.79 \mathrm{MW}$. Based on the priority ranking in Table X, DG 2 shall supply the remaining demand of Load 1, equal to $160 \mathrm{~kW}$. However, its generation capacity was reached before matching the remaining demand of Load 1. DG 2 supplies preferentially 1.66MW to Load 2 plus $130 \mathrm{~kW}$ to Load 1 .The $30 \mathrm{~kW}$ remaining are dispatched by DG 3 .

\section{Efficient Dispatch Control}

As with the big synchronous generators, the small ones do not have their maximum performance when they are operating at their maximum power. For that reason, the third simulated control method is based on the operation of the DG units at their maximum performance.

Each DG has its own dispatch center which controls the DG to supply the most priority related load and exchanges information with the other centers about the produced power and the demand from the other loads. The efficient dispatch control is therefore decentralized with the purpose to operate the DG units at their maximum performance and with minimal power exchange from the supply utility. As the previous described method, communication technology plays an important role making it possible the concept of virtual power plant (VPP).
When the load related to a given DG is greater than the DG efficient power production, then based on the information from the other dispatch centers the local center makes the decision about which DG are enabled to complement that demand.

The greatest efficiency of the three applied DG synchronous machines is the same and lies between $1.38 \mathrm{MW}$ and $1.60 \mathrm{MW}$ as given by the machines datasheet. Table XII presents the dispatch results for a demand condition required at about $6 \mathrm{am}$ as shown in Figure 2.

Table XII. - Simulation result of the Efficient Dispatch Control.

\begin{tabular}{|c|c|}
\hline DEMANDED POWER & DG GENERATED POWER \\
\hline Load 1: 1.56MW & DG 1: 1.46MW \\
\hline Load 2: 1.38MW & DG 2: $1.44 \mathrm{MW}$ \\
\hline Load 3: 1.34MW & DG 3: $1.38 \mathrm{MW}$ \\
\hline इLoad: $4.28 \mathrm{MW}$ & $\Sigma \mathrm{DG}: 4.28 \mathrm{MW}$ \\
\hline
\end{tabular}

In order to accomplish the efficient dispatch control it is necessary that each DG operates within its efficient power range. For the chosen load operating point, DG 1 generates $1.46 \mathrm{MW}$, which is within its efficient power range, DG 2 in turn increases its production to $1.44 \mathrm{MW}$ to supply its associated load and complement load 1 demand, also it operates within its efficient power range, and DG 3 fulfills the production, yet operating close to its lower range efficient power.

Figure 7 shows the total demand curve (upper curve) taking into account the constant and variable load of the distribution network and also the total demand of the three variable loads ( $\Sigma$ Variable Load). The production of each DG is also depicted (DG 1, DG 2 and DG 3) as well as the total production ( $\Sigma \mathrm{DGs})$. The difference shown in Figure 7 between the upper curve and the total variable load curve represents the system constant power which adds up 5.69MW.

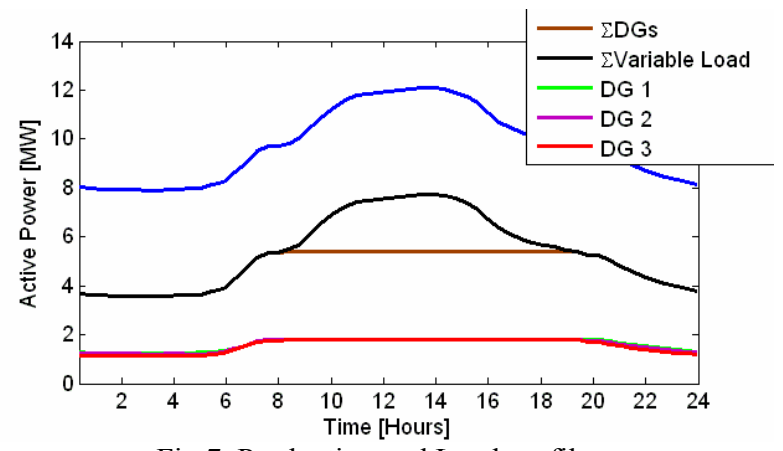

Fig.7. Production and Load profile.

Fig.7. DG generation and load profiles.

As each DG unit aims to supply its related variable loads, the demand curve is superior to the total DG production what means that there is no power exportation from the DG to the network.

It is noteworthy that during the period approximately from $8 \mathrm{am}$ to $7 \mathrm{pm}$ the utility supplies part of the demand 
of the variable loads because the DG have reached their capacity whose summation is inferior to the total demand of the variable loads. However, the VPP contributes to chop off the peak demand. During off-peak condition, the DG set are able to match their related loads. Conditions which the maximum efficiency is not possible to be complied by all generators may occur. In these cases, the control strategy seeks that each unit production moves as much as possible nearer the range of maximum efficiency. When there are a mix of DG from different energy resources, size and efficiency, the efficient dispatch control becomes more dynamic, however the control concept is still suitable.

\section{Conclusion}

This paper has presented the application of dispatch methods on a practical distribution feeder with a cluster of distributed generation connected to the power network comprising a virtual power plant. A multi-objective performance index has been used to assess the most appropriate connection nodes for the distributed generators. The multi-objective function is weighted to assign practical consideration to each function term. Different weighting factors may result in different locations. However, the experience or the most critical aspects of the evaluated system can be weighed up. Two control types for the distributed generators operation, with constant voltage and constant power factor, have been considered to evaluate the effect on the performance index. The best performance index was found for the DG control with fixed power factor. With the optimal allocation of the DG units, it has been observed an improvement of the voltage on the most distant nodes from the generators and the real decrease in the network active power losses. Most utilities do not intend the DG to attempt to regulate the voltage because that would interfere with utility voltage regulation equipment and increase the chances of supporting an island. Multiple DG would interfere with each other. Small DG is simply not powerful enough to regulate the voltage and will be dominated by the daily voltage changes on the utility system. Small DG is almost universally required to interconnect with a fixed power factor or fixed reactive power control. Nevertheless, the DG when collectively controlled may be required to provide ancillary services such as voltage control. The efficient dispatch control has shown suitable results, however it has been noted that according to the load profile and the DG capacities, the control strategy may not be complied over the entire demand time span. Yet, the control method can still pursue the DG operation near the maximum efficiency. The VPP shall become a reality in a near future, promoting the widespread use of renewable resources, and with that the control systems must be readapted to accommodate this new reality.

\section{Acknowledgement}

The authors acknowledge the Brazilian financial agencies FINEP - Financiadora de Estudos e Projetos and CNPq -
Conselho Nacional de Desenvolvimento Científico e Tecnológico for their valuable support.

\section{References}

[1] D. Pudjianto, C. Ramsay e G. Strbac, "Virtual power plant and system integration of distributed energy resources", in IET Renewable Power Generation, 2007, Vol. 1, pp.10-16.

[2] M. Scheibe, "Flexible Electricity Network to integrate the expected energy evolution". Available in: www.fenixproject.org. Accessed in: 29 March 2009.

[3] I. El-Samahy and E. El-Saadany, "The Effect of DG on Power Quality in a Deregulated Environment", IEEE Power Engineering Society General Meeting, 2005, Vol.3, pp.2969-2976.

[4] Z.A. Styczynski and K. Rudion, "Ancillary Services by VPP”, Kasseler Symposium Energie-Sytemtechnik, 2009. Fraunhofer IWES 2009, pp.80-96.

[5] L.F. Ochoa, A.P. Feltrin and G.P. Harrison, "Evaluating Distributed Generation Impacts with a Multiobjective Index". IEEE Trans. on Power Delivery, Vol. 21. No.3, July 2006, pp.1452-1458.

[6] E. A. Setiawan, "Concept and Controllability of Virtual Power Plant”, PhD Thesis, Kassel University, Germany, 2007.

[7] Procedimentos de Distribuição de Energia Elétrica no Sistema Elétrico Nacional - PRODIST. Available: $\mathrm{http}: / / \mathrm{www}$. aneel.gov.br/area.cfm?idArea $=82$ (in Portuguese).

[8] Procedimentos de Distribuição de Energia Elétrica no Sistema Elétrico Nacional - PRODIST. Módulo 3 Acesso ao Sistema de Distribuição (in Portuguese).

[9] Procedimentos de Distribuição de Energia Elétrica no Sistema Elétrico Nacional - PRODIST. Módulo 8 Qualidade da Energia Elétrica (in Portuguese).

[10] Procedimentos de Rede. Submódulo 3.6 Requisitos Técnicos Mínimos para a Conexão à Rede Básica (in Portuguese).

[11] M. Chis, M.M.A. Salama and S. Jayaaam, "Capacitor placement in distribution systems using heuristic search strategies", in IEEE Proc. Gener. Transm. Distrib., 1997, Vol.3, p. 225- 230.

[12] Southern California Edison. Available: www.sce.com. Accessed in: 08 Jul. 2009.

[13] A. Barin, L.N. Canha, R.Q. Machado, A.R. Abaide E. Maziero and G. Arend, "Analysis of the Impacts of Distributed Generation Sources considering the Appropriate Choice of Parameters in a Multi-objective Approach for Distribution System Planning". 5th International Conference on European Electricity Market, 2008, EEM 2008, May 2008, pp.1-6. 